\title{
Overeducation, Job Competition and Unemployment ${ }^{*}$
}

\author{
Joan Muysken \\ Department of Economics and Maastricht Economic Research Institute on Innovation and Technology \\ Maastricht University \\ P.O. Box 616, 6200 MD Maastricht \\ The Netherlands \\ j.muysken@algec.unimaas.nl \\ http://www.unimaas.nl/ fdewbae/jmuysken.htm
}

\author{
Bas ter Weel \\ Maastricht Economic Research Institute on Innovation and Technology \\ Maastricht University \\ P.O. Box 616, 6200 MD Maastricht \\ The Netherlands \\ b.terweel@merit.unimaas.nl \\ http://meritbbs.unimaas.nl/staff/bas/terweel.html
}

\begin{abstract}
The changing wage and employment structure in some OECD countries has been attributed to increased levels of education and technical change in favour of skilled workers. However, in the Netherlands and some other OECD countries the wages of skilled workers did not rise, whereas investment in skills rose dramatically. This paper offers a theory which is able to explain the dramatic increase in the level of education and skills without rising wages since the early 1980s. In this respect, we integrate the supply side framework (human capital investments) and the demand side (containing endogenous skill upgrading as a result of job competition and screening) in a general equilibrium model. In this way we provide a theory for the empirical observation of rising unemployment levels among unskilled workers and rising employment levels of skilled workers with relatively stable wages.
\end{abstract}

Keywords: $\quad$ human capital; unemployment; matching; job competition JEL Classification: $\mathrm{j} 24 ; \mathrm{j} 31 ; \mathrm{j} 41 ; \mathrm{j} 64$

* This paper has been presented at the European Association of Labour Economists Annual Conference 1999, Regensburg, Germany, 23-26 September. Seminar participants, particularly Frank den Butter and Henri de Groot, are gratefully acknowledged for their comments. We also want to thank Daron Acemoglu, Hugo Hollanders, Mark Sanders and Thomas Ziesemer for valuable suggestions and comments to improve this paper. Of course the usual disclaimer applies. 


\section{Introduction}

The structure of wages and employment has shifted in favour of skilled workers in many OECD countries over the past decades. ${ }^{1}$ Many studies have observed polarisation of the wage structure in the United States and the United Kingdom, while in many European countries the adjustment process went mainly through rises in unemployment among unskilled workers (e.g. Card, Kramarz and Lemieux, 1996, Berman, Bound and Machin, 1998 and Machin and Van Reenen, 1998).

Various reasons have been brought forward in the literature for rising European unemployment levels and a relatively stable wage. ${ }^{2}$ It is often attributed to the generosity of the welfare state, which leads to a high degree of upward wage pressure for unskilled labour, resulting in too high real wages for the relatively unskilled. Downward labour market rigidities as opposed to highly flexible financial markets also lead to out of equilibrium situations, resulting in unemployment levels higher than the natural rate levels. In addition, it is argued that the productivity slowdown since the first oil crisis and the resulting (skill-biased) technical change have raised the natural rate of unemployment. Finally, European systems of wage bargaining result into too high wages, which in turn induce a too high level of unemployment. Wasmer (1999) argues in this respect that the increase in the share of temporary work in total employment has negatively affected the bargaining position of workers with short-term contracts. He finds evidence that this evolution has also substantially affected unemployment.

Another interesting factor influencing the European unemployment problem, which is not touched upon yet, is the observation of dramatic increases of levels of education during the last decade, which did not go along with rising wage levels or wage premiums on

\footnotetext{
${ }^{1}$ See Chennells and Van Reenen (1999) and Sanders and Ter Weel (1999) for recent overviews.

${ }^{2}$ See e.g. Layard and Nickell (1986), Layard, Nickell and Jackman (1991), Sarantis (1993), Phelps (1994), Madsen (1998) and Nickell (1998). A particular interesting reference is Phelps and Zoega (1998) who argue that the increase in the unemployment rate in the 1970s and 1980s is caused by both increasing real interest rates, which have driven up mark-ups, and increasing taxes, unemployment benefits, and social expenditures, which made it profitable to quit and change jobs thereby pushing up (real) wages above their equilibrium levels.
} 
skilled labour. For example, in the Netherlands and Sweden the supply of skilled labour has increased since the 1970s, but the returns to education and investment in skills have declined strongly and are only recovering gradually, whereas attainment levels - if these levels declined at all - have recovered strongly. Gottschalk (1997) observes that "the relatively small increase in inequality in the Netherlands reflects a decline in the college premium, which largely offsets the substantial increase between experience groups and the increase in inequality within groups." This decline is according to Gottschalk due to the large increase in the supply of college graduates. Topel (1997) observes the same phenomenon for Sweden. ${ }^{3}$ An OECD (1996) study adds to this that during the 1980s dispersion of earnings increased strongly only in the United Kingdom; Austria, Belgium, Portugal and Spain faced only a slight increase. Wage dispersion decreased in Germany and France and there was no clear change in Italy. ${ }^{4}$

These observations of increased education without further wage dispersion can be explained in different ways. First, these observations indicate to a certain extent overinvestment in education and skills. Freeman (1976) and Rumberger (1981) examined this issue thoroughly when in the 1960s the United States faced this problem. They described the falling (net) returns to investment in human capital and concluded that overeducation led to crowding out of skills. However, the reason why workers overinvest in education is not so obvious from these studies.

Second, as Acemoglu (1998) points out, new technologies may not be complementary to skills by nature, but by design. He shows that the direction of technical change can

\footnotetext{
${ }^{3}$ Topel (1997) presents the Swedish situation and shows a sharp decrease in the college premium from the late sixties onwards, and again a small increase after the mid-eighties. Male school enrolment also falls sharply in the early seventies "which shows that college enrolments do respond to declining returns to schooling" (p. 69). However, Topel does not comment on the much stronger increase in school enrolment in the late eighties and early nineties, when compared to the very modest increase in the college premium. With respect to the latter he comments that "... the returns to education in Sweden remain extraordinary low" (p. 70).

${ }^{4}$ Ter Weel (1999) shows an index of the log hourly wages of employees in the Netherlands and the difference in log hourly wages between the $90^{\text {th }}$ and $10^{\text {th }}$ percentile of the wage distribution. In contrast with findings for the United Kingdom and the United States, wage dispersion between the highest and lowest earners fell in the Netherlands in the 1990s and only rose by some four percent in the period 19861998.
} 
explain why the demand for skills and the college premium increased sharply following the large increase in the supply of skills, and also why as opposed to the skill-replacing technical advances of the eighteenth century, today most new technologies appear to be skill-complementary - as in Griliches (1969). ${ }^{5}$ Although there is in general agreement that demand has shifted towards the skilled due to the fact that new technologies should be more skill-complementary today than in the past, Acemoglu's approach is not able to explain the increase in the supply of skilled workers which goes along with non-rising wages. ${ }^{6}$

Third, it has been argued that although technology can account for a significant part of the rising unemployment among unskilled workers, other factors play a role too. Allen (1996), investigating the United States, and Machin and Van Reenen (1998), in an empirical investigation of seven OECD countries, suggest that technical change alone can only account for a third or less of the changes in employment shares. Murphy, Riddell, and Romer (1998) - in a comparative study of the United States and Canada - argue that differences in the demand for workers do not account for the discrepancies in income. They note that in Canada the government had adopted a variety of post-secondary educational policies that boosted the number of workers at that level of education. This resulted in a lower wage differential between skilled and unskilled workers compared to the United States. Hence, it is the supply of educated workers that explains the difference.

Finally, Nickell and Bell (1995) investigate whether increased mismatch can explain the rise in European unemployment levels. However, they argue that there has been relatively little increase in mismatch and that most of the increase in European unemployment has other roots.

\footnotetext{
${ }^{5}$ See also Katz and Murphy (1992) and Autor, Katz and Krueger (1998).

6 Acemoglu (1999) offers a theory in which these labour market developments may be caused by a qualitative change in the composition of jobs. He argues that an increase in the proportion of high-skilled workers or skill-biased technical change can create this change in composition by considering a pooling and segregation equilibrium. In the former both low- and high-skilled workers are employed in the same jobs and wage differentials are compressed. In the latter, firms separate between jobs for low- and highskilled workers and wage inequality is higher than in the pooling equilibrium. Becker and Murphy (1992) and Bolton and Dewatripont (1994) also provide theoretical studies of this process.
} 
We suggest an alternative explanation to the observation of rising investments in education and skill levels among workers, while the reward is not rising and unemployment is not falling. We suggest a framework in which investment decisions do not only hinge upon the expected future wage. Motivated by this reasoning we build on and extend the work of Pissarides $(1990)^{7}$ on job matching and unemployment by including two types of workers, skilled and unskilled, thereby creating a dual labour market and by integrating the supply-side approaches of Schultz (1961) and Becker (1962) on human capital formation and the demand side frameworks developed by Spence (1973) and Thurow (1975) on screening and job competition, respectively. ${ }^{8}$

In doing so, we start from the premise of a kind of dual labour market consisting of skilled and unskilled labour - as in Bulow and Summers (1986), Davis and Reeve (1997), De Groot and Van Schaik (1997) and Davis (1998) - but allow skilled workers to work in an unskilled job. In our general equilibrium model employers demand skilled and unskilled labour to produce two types of goods. Since only a limited number of jobs are available in both sectors, an increased supply of skilled workers leads to full employment in the skilled sector, while the remaining skilled workers are temporarily hired in unskilled jobs. Hence, unskilled labour will be crowded out of the labour market into unemployment, explaining the dramatic rise in unemployment among unskilled workers in most European countries. This phenomenon is known in the literature as bumping down of skilled workers, since these workers wait for an opportunity to find a job in the skilled sector - cf. Borghans and De Grip (2000) which contains several contributions on bumping down. As we will show, bumping down of skilled labour into unskilled jobs is also an explanation of the persistent level of overeducation in many countries.

Job search is a major component of our model. Unlike Pissarides (1990), we combine job

\footnotetext{
7 See also Mortensen and Pissarides (1994) and Pissarides (1994).

${ }^{8}$ Although Pissarides (1990), Layard, Nickell and Jackman (1991) and Phelps (1994) build models which treat both sides of the labour market, the relationship between job competition models, human capital theory and matching theory is never explicitly stated and or investigated. In Muysken and Ter Weel (2000) we also develop a framework in which the interaction of schooling decisions, search duration, unemployment, skill differentials and the level of wages is provided. A drawback of that approach is that we are not able to explain the perturbing phenomenon of dramatically rising unemployment rates in the
} 
search with a process of screening and job competition and with human capital investment. As a result, the impact of human capital investment is not solely aimed at increasing the expected future wage but also to both give a positive 'signal' to the employer (who is screening the labour market for workers) and to enter the 'labour queue' at the highest possible rank. This behaviour is apparent for instance in the Netherlands, where many students try to obtain additional knowledge and skills by taking as many courses as they can besides the ordinary curriculum. The effect of this overinvestment in skills is that employers, knowing this behaviour, ask for higher skills than necessary for a particular vacancy. Because of the excess supply of skilled workers they will always find someone either giving the best signal or on top of the queue. This in turn induces workers to even more invest in human capital to give an even better signal and to enter the queue even higher. We show that this mechanism applies with non-rising wages for skilled workers. This mechanism enables us to explain in the context of a general equilibrium model a rising supply of skilled workers when wages are not increasing.

The plan of the paper is as follows. Section 2 analyses the basic features of the model and contains the background for the rest of the paper. Section 3 deals with unemployment and wage determination among workers and employers. Section 4 endogenises the supply of labour and analyses the model when employers screen workers and workers have to compete for jobs. Section 5 concludes.

1980s. Moreover, there are no links to the goods market, so that we are not able to construct a general equilibrium model. 


\section{The Basic Model}

We first outline the basic part of the model and explain its steady state properties. The basic properties of the model follow Acemoglu (1998), Davis and Reeve (1997) and Davis (1998), but do not take into account international trade. In this general equilibrium model we distinguish between skilled and unskilled workers - indicated 'skills' $H$ and 'labour' $L$ with wages $w_{H}$ and $w_{L}$, respectively, and relative wage $\omega=w_{H} / w_{L}$. These workers produce the skill-intensive good $X$ and the labour-intensive good $Y$. Both the goods markets and the labour markets are characterised by perfect competition.

The novel element that we introduce here in this model is that we assume that for skilled workers search effort is involved in matching jobs and workers and hiring costs have to be made. As we will show this will also affect human capital accumulation by skilled workers. In contrast unskilled workers do not invest in human capital and are matched to the relevant jobs in the production of both goods without any costs.

In this section we will analyse the matching process and its impact for a given labour market tightness under perfect competition on the labour market. In the next section we will show how labour market tightness is determined, by its impact on wage bargaining on the labour market.

\section{A. Production}

Good $X$ is the skill-intensive good and good $Y$ the labour-intensive one. Both goods markets are characterised by perfect competition. Consumers value both goods according to the following utility function:

$$
\Omega=\left[X^{\rho}+Y^{\rho}\right]^{1 / \rho}, \quad \rho<1,
$$


where the elasticity of substitution between $X$ and $Y$ equals $1 /(1-\rho)$. The prices of the goods are $P_{X}$ and $P_{Y}$ and the relative price is defined as $P=P_{X} / P_{Y}$. Defining total income $I$ as $P_{X} X+P_{Y} Y$, maximisation of utility subject to the budget constraint yields

$$
\frac{X}{Y}=\left[\frac{P_{X}}{P_{Y}}\right]^{\frac{-1}{1-\rho}} .
$$

This result implies that the relative consumption of the skill-intensive good is inversely related to its relative price.

The production of both goods is represented by the following Cobb-Douglas production functions:

$$
X=H_{X}^{\alpha} L_{X}^{1-\alpha}
$$

and

$$
Y=H_{Y}{ }^{\beta} L_{Y}{ }^{1-\beta},
$$

with $0 \leq \beta<\alpha \leq 1$. The restriction $\beta<\alpha$ implies that $X$ is the skill-intensive and $Y$ the labour-intensive good.

\section{B. Matching Skills to Jobs}

In the steady state neither job creation nor job destruction do take place. However, because of their finite lives, skilled workers quit their jobs at an exogenous rate $x$. New skilled workers enter the labour market at the same rate and try to obtain a skilled job, provided it pays a higher wage, i.e. $\omega>1$. Employers require these new skilled workers to produce both kinds of goods and hence search for them. 
The resulting matching process determines the rate at which a vacant skilled job becomes filled, i.e.

$$
\frac{m}{v}=m(\theta), \quad m_{\theta}, m_{\theta \theta}<0
$$

where $m / v$ is the matching rate, $m$ (.) represents the matching function and $\theta=v / u_{H}$ is defined as labour-market tightness $-m, v$ and $u_{H}$ are the rate of matches, vacancies and bumping down of skills into unskilled jobs, respectively. ${ }^{9}$ We denote $u_{H}$ as bumping down of skills, because we assume that during the search process for a skilled job, a skilled worker occupies an unskilled job. Alternatively, one could argue that skilled workers remain unemployed when searching for a skilled job. However, recent evidence brought together by e.g. Gautier (1999) suggests that skilled workers occupy unskilled jobs when they cannot immediately be assigned to skilled jobs.

From (4) it follows that the mean search duration is related to labour market tightness as follows:

$$
d(\theta)=\frac{1}{\theta m(\theta)} . \quad \mathrm{d}_{\theta}<0
$$

(5) exhibits the result that when the skilled labour market is tighter (i.e. $\theta$ is high), search duration for skilled workers will be lower. This is a straightforward result, since a high number of vacancies relative to the number of searchers makes it easier for skilled workers to find a job and therefore reduces the period of search.

Finally, in the steady state, underemployment of skilled workers equals:

\footnotetext{
9 We assume the initial matching function $M(u, v)$ to be linear homogenous in unemployment and vacancies. Pissarides (1979), Blanchard and Diamond (1990), Layard, Nickell and Jackman (1991) and Romer (1996) show that constant returns to scale is a satisfactory approximation to reflect the matching process and to adopt an appropriate matching function.
} 


$$
u_{H}^{*}=\left[1+\frac{1}{x d(\theta)}\right]^{-1} \quad \frac{d u_{H}^{*}}{d \theta}<0
$$

\section{Demand for Labour and Supply of Goods}

The process of search described above is taken into account when we consider the demand for skills. However, in this section we assume labour market tightness to be given. We will endogenise this in the next section, when we analyse the impact of labour market tightness on wage bargaining.

Essential in our analysis is the notion that an open vacancy represents search and hiring cost to the firm of on average $\gamma_{0}>0$ per period of time - cf. Pissarides (1990). Hence, the expected capitalised value of the firm's hiring cost should be added to the wage costs in the demand function for skills. To compensate for these hiring costs, the firm will offer a new worker a lower wage. Assuming perfect competition also on both labour markets, profit maximisation subject to (3) then yields

$$
w_{H}+\frac{(r+x)}{m(\theta)} \gamma_{0}=\alpha P_{X}\left[\frac{H_{X}}{L_{X}}\right]^{\alpha-1}=\beta P_{Y}\left[\frac{H_{Y}}{L_{Y}}\right]^{\beta-1}
$$

and

$$
w_{L}=(1-\alpha) P_{X}\left[\frac{H_{X}}{L_{X}}\right]^{\alpha}=(1-\beta) P_{Y}\left[\frac{H_{Y}}{L_{Y}}\right]^{\beta} \text {. }
$$

In (7a) the last term of the left-hand side is the expected capitalised value of the firm's hiring cost. It varies positively with the interest rate $r$ and the quit rate of skills $x$; it varies negatively with the matching rate $m$. Note that if the firm had no hiring costs, $\gamma_{0}$ would equal zero and (7a) would reduce to the standard marginal productivity condition for employment in the steady state. We will consider only situations in which $\gamma_{0}$ is larger than zero. 
To compute the relative wage, we eliminate $H_{X} / L_{X}$ and $H_{Y} / L_{Y}$ from (7). This yields:

$$
\omega=\frac{w_{H}}{w_{L}}=\psi_{1}\left[\frac{P_{X}}{P_{Y}}\right]^{\frac{1}{\alpha-\beta}}-\frac{(r+x)}{m(\theta)} \frac{\gamma_{0}}{w_{L}},
$$

where $\psi_{1}^{\alpha-\beta}=\alpha^{\alpha}(1-\alpha)^{1-\alpha} / \beta^{\beta}(1-\beta)^{1-\beta}$. The intuition behind this relationship is that when the relative price $P$ increases, firms make higher profits producing good $X$. Therefore, skills will be lured away from the production of good $Y$ and will be utilised in the production of good $X$. We define this relationship between $\omega$ and $P$ as the price determined real wage (PRW), which is represented graphically in the second quadrant of Figure 1. From (8) it also follows that the relative wage is lower, given $P$, when we incorporate the costly matching process. Finally, labour market tightness has an impact on the wages of skills - cf. equation (4).

Following Davis (1998) we can also depict the PRW-curve as a negative relationship between $P$ and the wage for labour, $w_{L}$. Using $(7 \mathrm{~b})$, the following relative price is obtained:

$$
\frac{P_{X}}{P_{Y}}=\psi_{2}\left[\frac{P_{Y}}{w_{L}}\right]^{\frac{\alpha}{\beta}-1},
$$

where $\psi_{2}=\beta^{\alpha}(1-\beta)^{\alpha / \beta-\alpha} / \alpha^{\alpha}(1-\alpha)^{1-\alpha}$. (9) is depicted in the third quadrant of Figure $1 .^{10}$

To analyse demand for skills and labour more explicitly, we define total demand as

$$
H=H_{X}+H_{Y}
$$

and

$$
L=L_{X}+L_{Y}
$$

\footnotetext{
${ }^{10}$ In the figure the low-skilled wage is relative to the price $P_{Y}$, whereas the latter is normalised to unity.
} 
Arbitrage between sectors results in a negative relation between relative wages $\omega$ and relative demand for labour $h \equiv H / L .^{11}$ The demand curve for skills relative to labour will be downward sloping for two reasons. First a higher $\omega$ implies that skills become more expensive; hence they will be demanded less in the production of both goods. Second, apart from this direct effect, there also is an indirect effect. A higher relative wage means that the skill-intensive good becomes more expensive and therefore consumer demand will shift towards the skill-extensive good. The resulting downward sloping demand curve $h^{d}$ is presented in the first quadrant of Figure 1.

\section{Investment in Human Capital and Supply of Skills}

Supply of skills is determined by considering investment in human capital - cf. Davis and Reeve (1997). It is assumed that $N$ persons, each with a working life of $T$ years, enter the population each year, whereas $N$ old persons retire each year. Out of these newcomers, $E$ $(<N)$ persons will choose education during $j$ years $-j$ is exogenous. ${ }^{12}$ These $E$ skilled persons have an average efficiency $q>1$ which is also a measure of their skills - the efficiency of an unskilled person is normalised to unity. Hence, in the steady state we find in terms of efficiency units by definition:

$$
H^{S}=q E(T-j)
$$

and

$$
L^{S}=(N-E) T
$$

for the supply of skills and labour, respectively. The wage for labour is $w_{L}$ and employers pay $w_{H}$ per efficiency unit of skill. ${ }^{13}$

\footnotetext{
${ }^{11}$ This is elaborated in the Annex to this paper.

${ }^{12}$ The exogenous quit rate $x$ of skilled workers therefore is $x=1 /(T-j)$.

${ }^{13}$ In the analysis above, we did not distinguish between efficiency units and persons. However, demand for skills now should be interpreted in terms of efficiency units.
} 
Actually, the average skill $q$ of skilled persons is determined by the amount of aggregate new skills in the economy, $Q$, relative to the number of new skilled workers, $E$, i.e., $q=$ $Q / E$. The generation of $Q$ is assumed to be linear homogenous in $K$ and $E$, where $K$ represents an exogenous amount of educational capital. The generation of skills also increases in the number of years of education $j$ - which is given here. Moreover, the generation of skills has decreasing returns to skilled persons - i.e. $Q_{E}>0, Q_{E E}<0$. Therefore each additional skilled person will lower the marginal productivity of skills $Q_{E}$.

Anticipating our model of job competition below, we assume that persons are ranked such that they have sequentially access to education. This ranking can be random or based on reasons exogenous to this analysis. But next to this ranking we assume that each person that followed education embodies the marginal skills he or she has generated. As a consequence, following Becker (1962), the supply of skills relative to labour is determined by the following equality, given the relative wage $\omega$ :

$$
\int_{j}^{T} w_{H} Q_{E} e^{-r t} d t=\int_{0}^{T} w_{L} e^{-r t} d t
$$

This equation should be amended, however, since we assume that skilled workers when searching for a job are temporary working on labour jobs and then earn the unskilled wage. Therefore we should also take the given search duration $d$ into account. ${ }^{14}$ The equality of (12) then should be redefined as follows:

$$
\int_{j+d}^{T} w_{H} Q_{E} e^{-r t} d t+\int_{j}^{j+d} w_{L} e^{-r t} d t=\int_{0}^{T} w_{L} e^{-r t} d t
$$

From this equation it follows that the amount of skills that will be supplied at the relative wage $\omega$ is determined by

\footnotetext{
${ }^{14}$ Since we assume labour market tightness to be given in this section, search duration is given too, cf. (5).
} 


$$
\frac{\omega}{\Delta^{d}}=\frac{1}{Q_{E}} . \quad \text { with } \Delta^{d}=\frac{1-e^{-r j}}{e^{-r(j+d)}-e^{-r T}}+1
$$

Since $Q_{E}$ is a decreasing function of $E$, we obtain that $E$ is increasing in $\omega$ too. ${ }^{15}$ Hence we see from (11) that also the supply of skills relative to labour, $h^{s}=H^{S} / L^{S}$, is increasing in $\omega$. This relationship is presented as the supply curve $h^{s}$ in the first quadrant of Figure 1. From this figure we also observe that an increase in $d$ shifts the supply curve to the left leading to a higher $\omega$.

\section{E. General Equilibrium}

The first quadrant in Figure 1 shows how the equilibrium level of skills relative to labour, $h^{F}$, is determined by equality of relative supply and demand on the labour markets. The second quadrant shows the simultaneous existence of equilibrium on both goods markets, determined by the equilibrium level of relative wages and prices $\omega^{F}$ and $P^{F}$, respectively. Finally, the equilibrium wage for labour is $w_{L}^{F}$ as is shown in the third quadrant of the figure.

One should realise that in this situation underemployment of skilled workers occurs at the rate ${u_{H}}{ }^{*}$ - cf. (6). However, since we assume that skilled workers can always occupy an unskilled job, skills will always be employed. As a consequence unemployment will occur among labour at a rate $u_{H}{ }^{*} h^{F}$ - this can be considered as natural unemployment.

[insert Figure 1 over here]

\footnotetext{
${ }^{15}$ We assume that the amount of educational capital $K$ is such that $\omega>1$ holds for all relevant values of $E$.
} 


\section{Unemployment and Wage Bargaining}

The basic framework of the previous section now will be amended to include unemployment, apart from natural unemployment. For simplicity we assume that the unskilled wage is fixed by a minimum wage, while the skilled wage is determined by wage bargaining. ${ }^{16}$ Unemployment then is determined by a combination of the minimum wage and wage bargaining.

\section{A. The Minimum Wage}

Consider some fixed legal minimum wage for labour in real terms - for analytical convenience we express this relative to the price of the labour intensive good. Moreover, it seems reasonable also to index the other nominal element in wage costs, i.e the hiring costs $\gamma_{0}-$ they are also defined relative to the price of the labour intensive good.

The fixed real minimum wage $w_{L}{ }^{*}$ lies above the equilibrium wage for labour, $w_{L}{ }^{F}$ in Figure 1. Since the minimum wage $w_{L}{ }^{*}$ exceeds the market wage for labour $w_{L}{ }^{F}$, good $Y$ will be relatively expensive and the relative price of $X$ will be below its equilibrium price level $P$. In terms of Figure 1: $P^{F}>P^{*}$, where $P^{*}$ is the relative price when the legal minimum wage is introduced. Moreover, the corresponding relative wage $\omega^{*}$ will be below its equilibrium level, i.e. $\omega^{*}<\omega^{F}$. It is important to note that by fixing the real minimum wage for labour, the relative wage is fixed too. This can be seen not only from Figure 1, but also from equations (8) and (9). ${ }^{17}$

Due to the higher minimum wage, relative demand for skills will increase to $h^{*}$, which implies $h^{*}>h^{F}$. One also sees from Figure 1 that at the relative wage $\omega^{*}$, the relative

\footnotetext{
${ }^{16}$ Muysken, Sanders and Van Zon (1999) provide a model in which bargaining takes place in both the skilled and unskilled labour market. The properties of the model are similar to the ones we obtain here.

${ }^{17}$ One should realise that by indexing the hiring costs $\gamma_{0}, \gamma_{0} / w_{L}$ is fixed too.
} 
supply of skills falls to $h^{F^{*}}$, which lies even further below relative demand for skills $h^{*}$. Thus unemployment will occur.

\section{B. Wage Formation and Labour Market Tightness for Skills}

Supply of skills will no longer be determined under perfect competition, i.e given the wage for skills. We now assume that skilled wages are determined by a Nash-bargaining game, in which the bargaining power, $0<\zeta<1$, of workers and employers is represented by $\zeta$ and $1-\zeta$, respectively. The resulting bargained real wage (BRW) is represented by

$$
\omega=(1-\zeta)+\zeta\left(g+\frac{\gamma_{0}}{w_{L}{ }^{*}} \theta\right)
$$

where $g$ represents the marginal productivity of skills relative to labour. Since $\gamma_{0}$ is the average hiring cost for each additional skilled worker, it is clear that these costs are added to the marginal product. As a consequence, BRW is increasing linear in labour market tightness. ${ }^{18}$ This relationship is represented in the first quadrant of Figure 2.

In spite of the bargaining process (15), the relative wage $\omega$ is fixed at $\omega$ * by equilibrium on the goods market (8). This means that the PRW is independent of $\theta$ and hence can be represented by a horizontal PRW curve in the first quadrant of Figure 2. However, $\omega^{*}$ is still, like $h^{*}$, conditional on the expected capitalised value of the firm's hiring cost - cf. (7). Therefore an increase in the average hiring costs, the interest rate or the quit rate, results in a lower $\omega^{*}$ and hence shifts the PRW-curve downwards.

From the first quadrant of Figure 2 one sees that labour market tightness will adjust in such a way that the bargained real wage is consistent with the fixed price-determined real wage. ${ }^{19}$ The resulting value is denoted by $\theta^{*}$ in Figure 2 .

\footnotetext{
${ }^{18}$ We ignore the possible relationship between productivity $g$ and labour market tightness $\theta$.

${ }^{19}$ See for a model with similar assumptions and properties Carlin and Soskice (1990).
} 
From equation (5) we know that the mean search duration now is determined by $d\left(\theta^{*}\right)$. Since the relative supply of skills is conditional on search duration, the $h^{s}$-curve in the second quadrant of Figure 2 is derived by substituting $d\left(\theta^{*}\right)$ in equation (14). Relative labour supply at $\omega^{*}$ then is given by $h^{F^{*}}$.

Finally, equation (6) is presented in the fourth quadrant of Figure 2. We know from this equation that in the steady state underemployment equals $u_{H}{ }^{*}$.

\section{Unemployment}

From Figure 1 we know that relative demand for labour is fixed at $h^{*}$ by the legal minimum wage - it is conditional on the expected capitalised value of the firm's hiring costs. In the second quadrant of Figure 2 demand for labour is represented by the vertical curve labelled $h^{*}$. For each amount of skills supplied $H^{s}$, potential employment of labour is now only $H^{s} / h^{*}$. However, skilled workers, when searching for a skilled job, occupy temporarily labour jobs. As a consequence, $u_{H}{ }^{*} H^{s}$ skilled workers are employed in a labour job. This implies a lower demand for labour, which therefore equals $\left(1 / h^{*}-u_{H}{ }^{*}\right) H^{s}$. Unemployment of labour, $u=U / L^{S}$, is then determined by

$$
u^{*}=1-\left(\frac{1}{h^{*}}-u^{*}{ }_{H}\right) h^{F^{*}} \text {. }
$$

Unemployment $u$ is typically increasing in $h>h^{F^{*}}$ and equals $u^{*}$ at $h=h^{*}$ as can be observed from the third quadrant of Figure 2. It is obvious from the above that unemployment $u^{*}$ is higher, the higher the legal minimum wage is. This can be easily seen from Figure 2: since a higher minimum wage leads to a lower $\omega^{*}$, the difference between $h^{*}$ and $h^{F^{*}}$ will increase for two reasons. First, a lower $\omega$ shifts $h^{F^{*}}$ to the right in the second quadrant. Second, a lower $\omega$ shifts the (conditional) $h^{*}$ curve to the left, as can be observed from the analysis concerning Figure 1. The resulting unemployment curve is depicted in the third quadrant of Figure 2. 
The analysis underlying Figure 2 can now be summarised as follows. Given the real minimum wage for labour $w_{L}{ }^{*}$, through arbitrage on the goods markets the relative wage is fixed at $\omega^{*}$. This implies that labour market tightness will become $\theta^{*}$ to set the bargained real wage also at $\omega^{*}$ - underemployment of skills then equals $u_{H}{ }^{*}$. In addition, the mean duration consistent with $\theta^{*}$ determines the supply of skills, represented by $h^{s}$. The relative wage $\omega^{*}$ then establishes relative demand and supply at $h^{*}$ and $h^{F^{*}}$, respectively. Finally, the information on $h^{*}, h^{s}$ and $u_{H}{ }^{*}$ determines the unemployment rate of labour at $u^{*}$.

Given the impact of duration on labour supply, one sees that unemployment of labour above its natural level is not only determined by the minimum wage, but also by the wage bargaining process. An increase in bargaining power of the workers will increase the bargained real wage and hence underemployment $u_{H}{ }^{*}$. Moreover, because of the increased mean duration of underemployment, supply of skills relative to labour at $\omega^{*}$ will decrease such that $h^{F^{*}}$ will be lower too. It is obvious that both factors contribute to a higher unemployment of labour at the same minimum wage. A similar observation holds for an increase in real hiring costs. However, this will also decrease the relative wage $\omega^{*}$ in relation to the fixed real minimum wage $w_{L}{ }^{*}-\mathrm{cf}$. (8) - which even leads to a further deterioration of unemployment. Finally one sees that the impact of a decrease in the minimum wage on unemployment of labour is clearly mitigated, through it adverse effect on the bargained real wage.

[insert Figure 2 over here] 


\section{Job Competition and Endogenous Skill Upgrading}

As we stated in the introduction, the supply of skills during the past decades is not likely to be the result of increasing returns to education. This is inconsistent with traditional human capital theory. Nonetheless, educational decisions are to some extent forward looking and not independent of returns. To explain this observation, but also to maintain the notion of forward looking behaviour, we introduced the impact of search duration in the investment decision on human capital. In the previous section we emphasised the impact of returns on this decision. Now we will add to that the insight that education can also be used directly to shorten search duration.

In general workers perceive that more job opportunities arrive when their level of education is higher. As Thurow (1975) states in his theory of the labour queue, one of the most important characteristics to increase employment opportunities is the level of education. This might be plausible for several reasons. For instance, Weiss (1995) points out that higher educated workers probably also have better unobservable characteristics like a better work attitude, a lower propensity to turnover and better health. Workers might use this correlation as a means to signal their abilities. Employers might also use this as additional information since education is an important characteristic in their hiring decision, i.e in screening the applicants. Both the signalling approach and the screening approach can be seen as important extensions to human capital theory with similar implications. Together they are dubbed by Weiss as the 'sorting' approach. ${ }^{20}$ Other approaches by e.g. Phelps (1998) argue that higher skilled workers are reducing training cost; Brunello and Medio (1996) regard education as an entry ticket because it reduces training costs and it signals unobserved ability; and finally Ter Weel (1999) argues that higher skills are more likely to be applicable in several different types of jobs and hence

\footnotetext{
${ }^{20}$ Weiss (1995) discusses several empirical findings with respect to the relationship between wages and education which can be explained better by sorting than by the learning explanation which is usually associated with human capital theory. A recent approach by Swinkels (1999) analyses the seminal work of Spence in a game-theoretic environment. His version of Spence's model analyses a model in which firms can make job offers before workers have completed their formal education. The outcomes of the model
} 
can be allocated to a wider spectrum of jobs than lower skills. This evidence indicates that education has a positive impact on the matching process described above.

For that reason we add to the matching function the notion that the probability of finding a match is increasing in $q$. However, these skills $q$ should be seen relative to the level of skills $q$ required by the employers. ${ }^{21}$ Hence, the matching function is extended to

$$
\frac{m}{v}=m\left(\theta, \frac{q}{q}\right), \quad m_{q}>0, m_{\theta}, m_{\theta \theta}<0, q \geq q
$$

The implications of the introduction of extended matching function in the above framework are twofold. First, individuals want to invest more in human capital to improve their labour market position. However, this is only possible when the years of education $j$ will increase - this will increase the marginal product in the generation of skills and hence the actual skills of each educated person. We assume that sufficient pressure will be built up to increase $j$ indeed, for the years of education were given until now. So everybody will invest more in skills, which is plausible since all skilled workers want to obtain a skilled job. It seems plausible, however, to assume that given the general increase in the level of skills, employers will also increase the level of skilled required, $q$. For simplicity we assume that on average the ratio between the supplied quality $q$ and the demanded quality $q$ remains unchanged. ${ }^{22}$ Hence, increased educational levels will not affect relative wages. This van be seen by introducing the new matching function (17) in equation (8) underlying the PRW curve in Figure 2. This yields:

$$
\omega=\frac{w_{H}}{w_{L}}=\psi_{1}\left[\frac{P_{X}}{P_{Y}}\right]^{\frac{1}{\alpha-\beta}}-\frac{(r+x)}{m(\theta, q / \underline{q})} \frac{\gamma_{0}}{w_{L}}
$$

predict that due to such offers workers become overeducated in order to separate themselves from less able workers.

${ }^{21}$ This could be interpreted as Spence's (1973) inference rule, which reveals that employers infer that they want to employ workers with skills of at least $q$. As a result, the rate at which a vacant job, requiring the perceived level of demanded skills $q$ becomes filled by a person with skill level $q$ can be described by (16).

${ }^{22}$ An alternative mechanism with the same outcome is suggested by Acemoglu (1999). He obtains in a segregation model that firms, when facing increased supply of skills, become more selective and screen more intensively. Hence $q$ increases to $q$. 
which shows that $\omega$ will not change when $q / q$ does not change. Hence the right part of Figure 2, i.e. the first and the fourth quadrant, is not affected by the analysis.

The second effect is that the increased years of education and therefore increased levels of skills have effects on the supply of skills relative to labour, which is presented as the supply curve $h^{s}$ in the second quadrant of Figure 2. It follows from the analysis in Section 2.D that when individuals invest more in education the $h^{s}$ curve shifts outward, simply because of increased skill supply at the same relative wage. This outward shift is presented in the first quadrant of Figure 3, together with the vertical relatiive demand curve at $h^{*}$.

Combining the effects of a non-changing $\omega$ according to (18) and the shift in the $h^{s}$ curve we observe the following. Since wages are at $\omega^{*}$, as a result of the legal minimum wage, the effect of an increased supply of skills is a new equilibrium supply $h^{F F^{*}}>h^{F *}>h^{F}$. This affects the rate of unemployment (16) in the following manner

$$
u^{*}=1-\left(\frac{1}{h^{*}}-u_{h}^{*}\right) h^{F^{*}}<u^{* *}=1-\left(\frac{1}{h^{*}}-u_{h}^{*}\right) h^{F F^{*}}
$$

This is shown in the lower quadrant of Figure 3.

As (19) shows, the increase in unemployment from $u^{*}$ to $u^{* *}$ is the result of an increase in the equilibrium level of the relative supply of skills from $h^{F^{*}}$ to $h^{F F^{*}}$. This implies an increased bumping down of labour by underemployed skilled workers. increases because relative supply of skilled workers increases at the same rate of underemployment. Referring to the observation at the beginning of this section, we have shown how job competition among skilled workers leads to $u^{* *}>u^{*}$ with unchanging relative wages $\omega^{*}$. The equilibrium supply of skills has increased, without an increase in skilled wage but with increasing levels of bumping down of skills into labour jobs and as a result increasing unemployment levels of labour. This increased number of skilled workers employed in unskilled jobs points towards a general level of overeducation, which is one 
of the contemporary peculiarities of many European labour markets, particularly the Dutch.

[insert Figure 3 over here] 


\section{Concluding Remarks}

The wages of the $90^{\text {th }}$ percentile of the wage distribution relative to the $10^{\text {th }}$ percentile of the wage distribution have not increased dramatically in for instance the Netherlands over the past fifteen years. In the 1990s the difference even fell, indicating decreasing polarisation in the wage distribution. Although this observation might exhibit the effects of the consensus policies among labour unions and employer's organisations, which resulted in wage moderation and better conditions for the unskilled and hence in a narrowing wage distribution since the late 1980s, the dramatic increase in educational attainment and the subsequent rising skill levels potentially suggest increasing wage dispersion.

In this paper we have formalised the observation of increasing supply of skills without rising wages. As a result of job competition among skilled workers, for a fixed number of skilled jobs, we have shown that an increase in the ratio of skilled to unskilled workers did not increase relative wages. These results fit the facts for the Netherlands and other European countries quite well, since educational attainment increased over the past decades whereas wages did not rise dramatically. The adjustment process went through on the one hand bumping down of skilled workers into unskilled jobs and on the other hand crowding out of unskilled workers into unemployment.

The observation on this adjustment process enables us to explain the persistent and high levels of overeducation in European countries, e.g. the Netherlands and Sweden. When education is used as a signalling device and is applied as an effective 'tool' to compete in the labour market, a higher level of education has a wage effect in that a higher level of education increases the opportunity to obtain a skilled job. However, the returns to marginal education are zero once a skilled job is acquired. In addition, bumping down will occur, such that skilled workers occupy unskilled jobs. Hence, overeducation is both present in skilled and unskilled jobs. 


\section{References}

Acemoglu, K. Daron (1998), Why Do New Technologies Complement Skills? Directed Technical Change and Wage Inequality, Quarterly Journal of Economics, vol. 113, pp. 1055-89.

Acemoglu, K. Daron (1999), Changes in Unemployment and Wage Inequality: An Alternative Theory and Some Evidence, American Economic Review, vol. 89, forthcoming December.

Allen, Steven G. (1996), Technology and the Wage Structure, NBER Working Paper No. 5534, Cambridge MA.

Autor, David H., Lawrence F. Katz, and Alan B. Krueger (1998), Computing Inequality: Have Computers Changed the Labor Market, Quarterly Journal of Economics, vol. 113, pp. 1169-1213.

Becker, Gary S. (1962), Investment in Human Capital: A Theoretical Approach, Journal of Political Economy, vol. 70, pp. 9-49.

Becker, Gary S. and Kevin M. Murphy (1992), The Division of Labor, Coordination Costs and Knowledge, Quarterly Journal of Economics, vol. 107, pp. 1137-60.

Berman, Eli, John Bound and Stephen Machin (1998), Implications of Skill-Biased Technological Change: International Evidence, Quarterly Journal of Economics, vol. 113, pp. 1245-79.

Blanchard, Olivier J. and Peter A. Diamond (1990), The Aggregate Matching Function, NBER Working Paper 4000, Cambridge MA.

Bolton, Patrick and Mathias Dewatripont (1994), The Firm as a Communication Network, Quarterly Journal of Economics, vol. 109, pp. 809-39.

Borghans, Lex and Andries de Grip (2000) (eds.), The Overeducated Worker? The Economics of Skill Utilization, Edward Elgar: Cheltenham (forthcoming, March).

Brunello, Giorgio and Alfredo Medio (1996), A Job Competition Model of Workplace Training and Education, Fondazione Eni Enrico Mattei Note di Lavoro Working Paper 75-96.

Bulow, Jeremy I. and Lawrence H. Summers (1986), A Theory of Dual Labor Markets with Application to Industrial Policy, Discrimination, and Keynesian Unemployment, Journal of Labor Economics, vol. 4, pp. 376-414.

Burdett, Kenneth and Eric Smith (1996), Education and Matching Externalities, in: Alison S. Booth and Dennis J. Snower, Acquiring Skills, Cambridge University Press: Cambridge, pp. 65-80.

Card, David, Francis Kramarz, and Thomas Lemieux (1996), Changes in the Relative Structure of Wages and Employment: A Comparison of the United States, Canada and France, NBER Working Paper 5487, Cambridge MA.

Carlin, Wendy and David Soskice (1990), Macroeconomics and the Wage Bargain: A Modern Approach to Employment, Inflation, and the Exchange Rate, Oxford University Press: Oxford.

Chennells, Lucy and John Van Reenen (1999), Technical Change and the Structure of Employment and Wages: A Survey of the Micro-Econometric Evidence, Institute for Fiscal Studies, mimeo March.

Davis, Donald R. (1998), Does European Unemployment Prop Up American Wages? 
National Labor Markets and Global Trade, American Economic Review, vol. 88, pp. 478-94.

Davis, Donald R. and Trevor A. Reeve (1997), Human Capital, Unemployment and Relative Wages in a Global Economy, NBER Working Paper 6133, Cambridge MA.

Freeman, Richard B. (1976), The Overeducated American, Academic Press: New York.

Gautier, Pieter A. (1999), Do More High Skilled Workers Occupy Simple Jobs during Bad Times?, Central Planning Bureau Working Paper 145, The Hague.

Gottschalk, Peter (1997), Inequality, Income Growth, and Mobility, The Basic Facts, Journal of Economic Perspectives, vol. 11, pp. 21-40.

Griliches, Zvi (1969), Capital-Skill Complementarity, Review of Economics and Statistics, vol. 51, pp. 465-68.

de Groot, Henry L. F. and Anton B. T. M. van Schaik (1997), Unemployment and Catching Up: Europe vis-à-vis the USA, De Economist, vol. 145, pp. 179-201.

Katz, Lawrence F. and Kevin M. Murphy (1992), Changes in Relative Wages, 19631987: Supply and Demand Factors, Quarterly Journal of Economics, vol. 107, pp. 35-78.

Kremer, Michael and Eric S. Maskin (1996), Segregation by Skill and the Rise in Inequality, MIT mimeo.

Layard, Richard and Stephen J. Nickell (1986), Unemployment in Britain, Economica, vol. 53, pp. S121-S69.

Layard, Richard, Stephen J. Nickell and Richard Jackman (1991), Unemployment: Macroeconomic Performance and the Labour Market, Oxford University Press: Oxford.

Machin, Stephen J. and John Van Reenen (1998), Technology and Changes in Skill Structure: Evidence from Seven OECD Countries, Quarterly Journal of Economics, vol. 113, pp. 1215-44.

Madsen, Jacob B. (1998), General Equilibrium Macroeconomic Models of Unemployment: Can They Explain the Unemployment Path in the OECD?, Economic Journal, vol. 108, pp. 850-67.

Mortensen, Dale T. and Christopher A. Pissarides (1994), Job Creation and Job Destruction in the Theory of Unemployment, Review of Economic Studies, vol. 64, pp. 397-415.

Murphy, Kevin M., W. Craig Riddell, and Paul M. Romer (1998), Wages, Skills, and Technology in the United States and Canada, in: Elhanan Helpman, (ed.), General Purpose Technologies and Economic Growth, MIT Press: Cambridge MA, pp. 283-309.

Muysken, Joan and Bas ter Weel (2000), Overeducation and Crowding-Out of LowSkilled Workers, in: Lex Borghans and Andries de Grip, (eds.), The Overeducated Worker? The Economics of Skill Utilization, Edward Elgar: Cheltenham, pp. 10932.

Muysken, Joan, Mark Sanders and Adriaan van Zon (1999), Wage Divergence and Asymmetries in Unemployment in a Model with Biased Technical Change, Maastricht Economic Research Institute on Innovation and Technology Research Memorandum 99-020, Maastricht.

Nickell, Stephen J. (1998), Unemployment: Questions and Some Answers, Economic 
Journal, vol. 108, pp. 802-16.

Nickell, Stephen J. and Brian D. Bell (1995), The Collapse in the Demand for the Unskilled and Unemployment in the OECD, Oxford Review of Economic Policy, vol. 11, pp. 40-62.

OECD (1996), Technology, Productivity and Job Creation, Paris: OECD.

Phelps, Edmund S. (1994), Structural Slumps: The Modern Equilibrium Theory of Unemployment, Interest and Assets, Cambridge MA: Harvard University Press.

Phelps, Edmund S. (1998), New Technologies and the Less-Qualified Worker: Intervening to Shore Up Inclusion and Releasing Enterprise to Rekindle Development, Paper presented at the fourth conference on job creation, employment and new technologies, IESE University of Navarra, Barcelona, June.

Phelps, Edmund S. and Gylfi Zoega (1998), Natural-Rate Theory and OECD Unemployment, Economic Journal, vol. 108, pp. 782-801.

Pissarides, Christopher A. (1979), Job Matching with State Employment Agencies and Random Search, Economic Journal, vol. 89, pp. 818-33.

Pissarides, Christopher A. (1990), Equilibrium Unemployment Theory, Basil Blackwell: Oxford.

Pissarides, Christopher A. (1994), Search Unemployment with On-the-Job Search, Review of Economic Studies, vol. 64, pp. 457-75.

Romer, David (1996), Advanced Macroeconomics, McGraw-Hill: New York.

Rumberger, Russell W. (1981), Overeducation in the U.S. Labor Market, Praeger Publishers: New York.

Sanders, Mark and Bas ter Weel (1999), Skill-Biased Technical Change: Theoretical Concepts, Empirical Problems and a Survey of the Evidence, Maastricht Economic Research Institute on Innovation and Technology, mimeo 1 December.

Sarantis, Nicholas (1993), Distribution, Aggregate Demand and Unemployment in the OECD Countries, Economic Journal, vol. 103, pp. 459-67.

Schultz, Theodore W. (1961), Investment in Human Capital, American Economic Review, vol. 51, pp. 1-17.

Spence, A. Michael (1973), Job Market Signalling, Quarterly Journal of Economics, vol. 88, pp. 355-74.

Swinkels, Jeroen M. (1999), Education Signalling with Preemptive Offers, Review of Economic Studies, vol. 66, pp. 949-70.

Thurow, Lester C. (1975), Generating Inequality, Basic Books: New York.

Topel Robert H. (1997), Factor Proportions and Relative Wages, Journal of Economic Perspectives, vol. 11, pp. 55-74.

Wasmer, Etienne (1999), Competition for Jobs in a Growing Economy and the Emergence of Dualism, Economic Journal, vol. 109, pp. 349-71.

ter Weel, Bas (1999), Changes in Job, Skill and Wage Structures: Evidence from the Netherlands 1986-1998, Maastricht Economic Research Institute on Innovation and Technology, mimeo 7 December.

Weiss, Andrew (1995), Human Capital vs. Signalling Explanations of Wages, Journal of Economic Perspectives, vol. 9, pp. 133-54. 


\section{Annex}

To analyse demand for skills and labour more explicitly, we define total demand for both skills and labour according to (9a) and (9b). Now if we define $h=H / L, h_{X}=H_{X} / L_{X}$ and $h_{Y}$ $=H_{Y} / L_{Y}$, we can derive that

$$
\frac{L_{X}}{L_{Y}}=\frac{h_{Y}-h}{h-h_{X}} .
$$

Using the arbitrage conditions, equation (3a) and (3b), yields

$$
h_{X}=\psi_{X}\left[\frac{P_{X}}{P_{Y}}\right]^{-\frac{1}{\alpha-\beta}}
$$

and

$$
h_{Y}=\psi_{Y}\left[\frac{P_{X}}{P_{Y}}\right]^{-\frac{1}{\alpha-\beta}},
$$

where $\psi_{X}{ }^{\alpha-\beta}=\beta^{\beta}(1-\beta)^{1-\beta} / \alpha^{\beta}(1-\alpha)^{1-\beta}$ and $\psi_{Y}{ }^{\alpha-\beta}=\beta^{\alpha}(1-\beta)^{1-\alpha} / \alpha^{\alpha}(1-\alpha)^{1-\alpha}$. Moreover, combining equation (2) and (3) also yields $L_{X} / L_{Y}$ as a function of relative prices:

$$
\frac{L_{X}}{L_{Y}}=\frac{h_{Y}{ }^{\beta}}{h_{X}{ }^{\alpha}}\left[\frac{P_{X}}{P_{Y}}\right]^{-\frac{1}{1-\rho}} .
$$

Substituting equation (A.2), (A.3), (9a) and (b) into (A.4) results in a relationship between $h$ and $P$ which represents the relative demand for labour as follows:

$$
h=P^{\frac{-1}{\alpha-\beta}} \frac{\psi_{X} \psi_{Y}{ }^{\beta} P^{\frac{-\rho}{1-\rho}}+\psi_{Y} \psi_{X}{ }^{\alpha}}{\psi_{Y}{ }^{\beta} P^{\frac{-\rho}{1-\rho}}+\psi_{X}{ }^{\alpha}} .
$$

This demand for skills relative to labour is negatively related to $P$ and hence $\omega$. The explanation is that when skills are more abundant, i.e. $h$ is higher, there will be a relatively higher production of $X$ and a relative lower production of $Y$. As a consequence, $P$ will fall. 
Figure 1

Basic Model

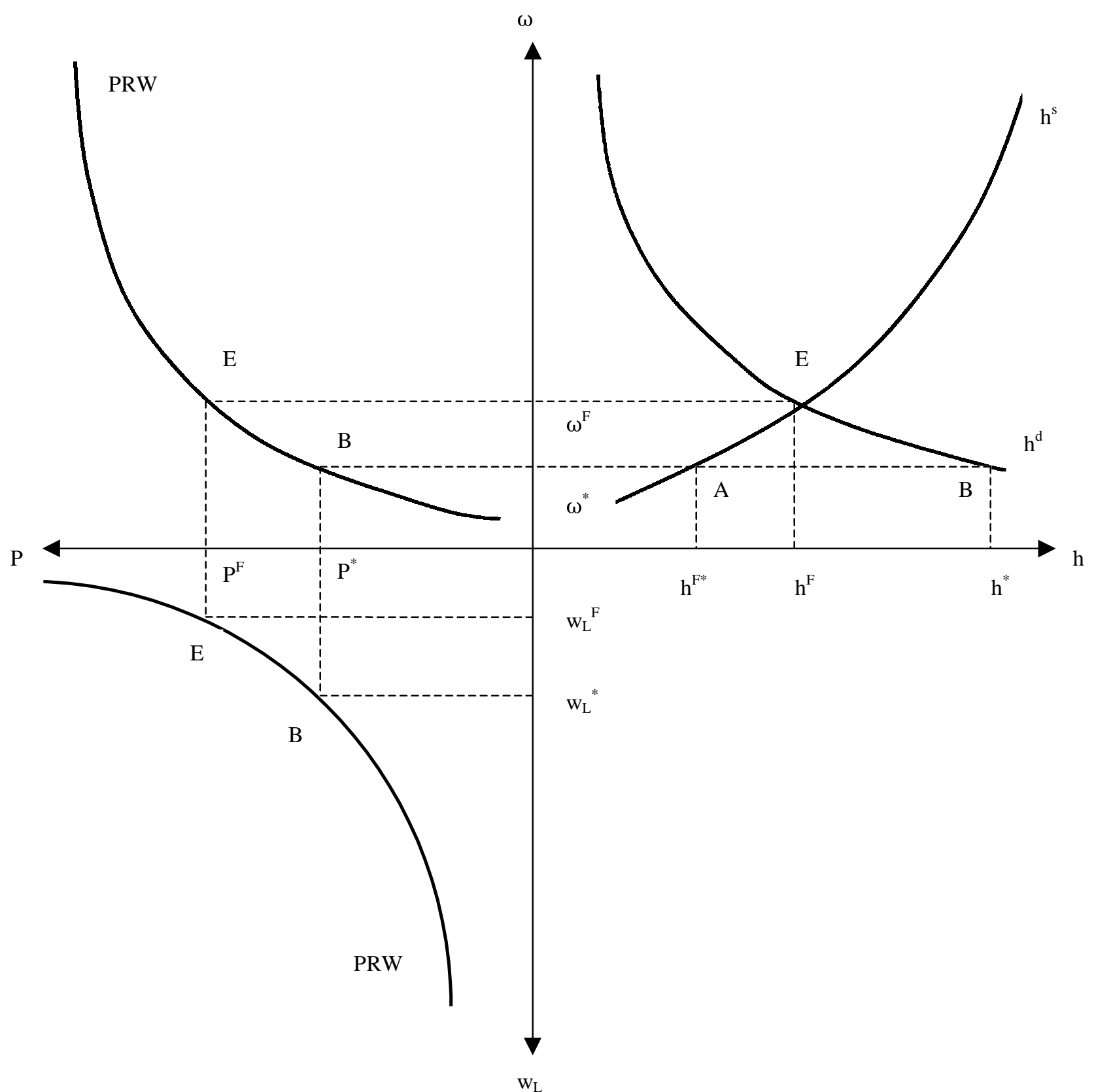


Figure 2

Labour Market Tightness and Unemployment

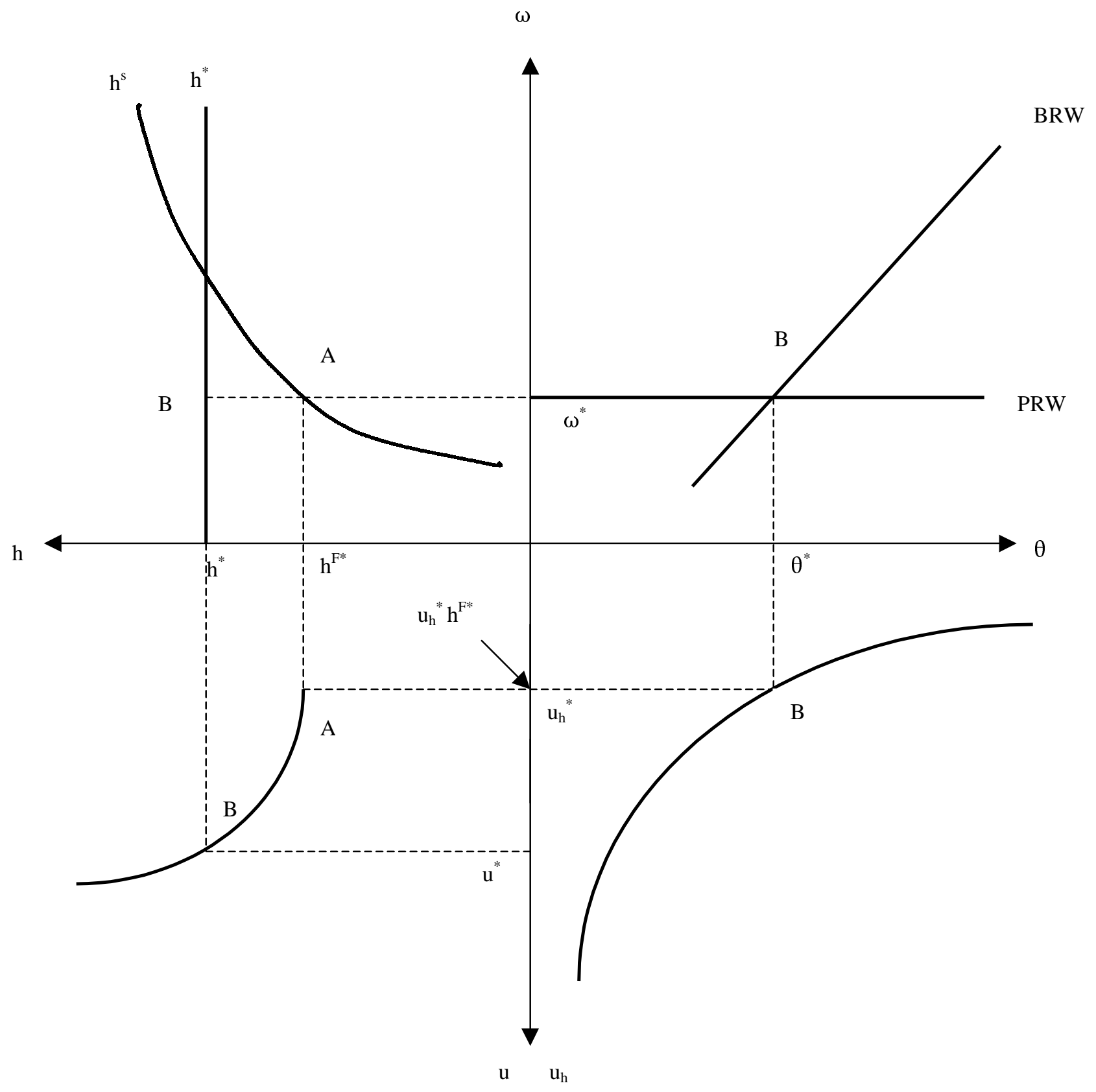


Figure 3

Increasing Supply of Skills

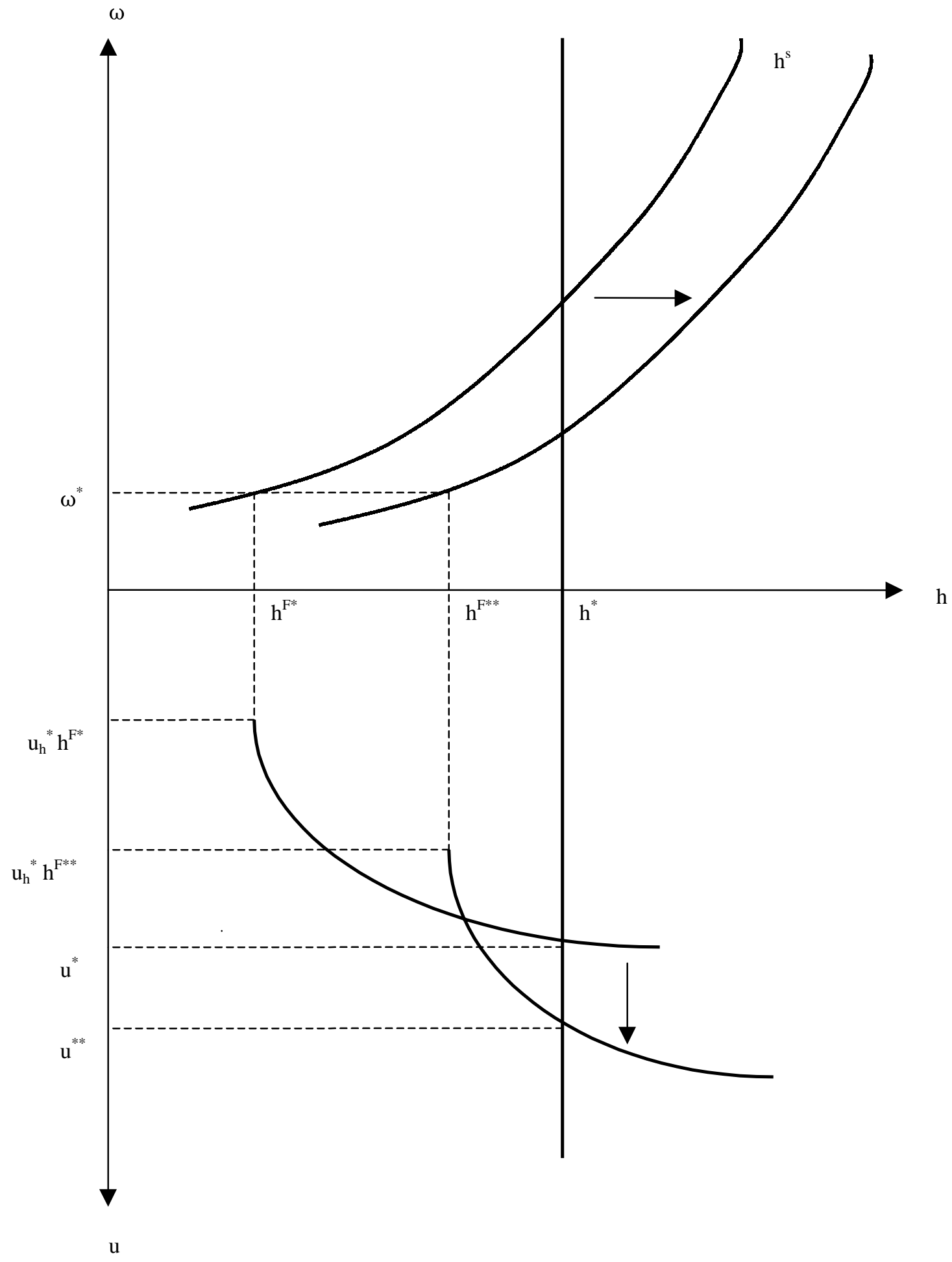

29 